\section{A CASE OF MULTIPLE SARCOMA.}

By SEYMOUR TAYLOR, M.D. ABERD., F.R.O.P. LOND., PHYSICIAN TO THE WEST LONDON HOSPITAL.

A MAN, aged 32 years, was sent to consult me on Jan. 7th, 1904, by Mr. F. E. Streeten. of Swindon. The patient was in his usual good health until the previous July, when he noticed a "lump" in the abdominal wall which appeared "to have sprung up suddenly in the night." It was unattended by pain. A few days afterwards he complained of cough which had continued up to the time when I saw him but which had not been attended by hæmoptysis, or expectoration, or night sweats, although he had lost flesh considerably. Since then numerous similar "lumps" had appeared all over the trunk, back and front. There was no history of syphilis. His parents were both living and healthy and there was no family history of tuberculosis. There was no history of any previous extensive disease of the skin but a slight patch of eczema had existed over the inner left ankle for some months.

The patient was admitted into the West London Hospital and on examination he was found to be a well-marle man, somewhat pallid and emaciated. When he had removed his shirt some tumours were noticed in the skin over the scapular regions. In appearance they gave one the suggestion that they were sebaceous cysts. But further examination failed to discover their porous outlets and, moreover, their consistence on digital examination pointed to their being subcutaneous new growths. On examining the front surface of the body an extraordinary condition of affairs was presented. Scattered over the abdomen and thoracic walls were a number of solid tumours, varying in size from that of a Tangerine orange (which was the first tumour the patient had noticed) to that of a large pea. The large growth was situated in the right side of the abdominal wall midway between the anterior superior iliac spine and the umbilicus, though slightly above this horizontal line. Its surface was red and granular in appearance, looking as though it was ulcerated; but there was no discharge or "weeping" of any kind, although yellowish scales of necrosed epidermis appeared between the granular nodules. On the opposite side of the abdominal wall in the corresponding site there was almost a similar lesion, the difference being that two contiguous tumours occupied the space filled by the tumour in the right side, while symmetrical growths were seen to exist between the larger ones described above and the nipples. Both mammæ were indurated and involved with the neoplasm, the skin, however, in these localities being as yet intact. Similar nodules, though not well seen in the illustration, were found in the skin over each fourth costal cartilage, and when one traced these-various growths they gave one the impression of a circular outbreak which involved the abdominal wall principally, but also the lower zone of the thorax to a lesser degree. This configuration, however, could only be accidental, as other tumours were found within this zone, and I know of no condition of vessels, whether appertaining to the circulatory or to the lymphatic system, which could give origin to this annular arrangement of the tumours. Other similar growths, though not so large, only two or three being of the size of nutmegs, were found over the front of the upper chest. The lymph glands of the groin were indurated and matted together but the skin moved easily over each mass. The glands of the axillæ were similarly affected though to a less degree. Those of the neck were unaffected.

The skin was fully moveable over each tumour and was not involved over the smaller ones, but over those which had attained a large size corresponcling to the bulk of a pigeon's egg the skin was reddened and glazed, whilst the superficial veins stretching over them were engorged and slightly varicose. In those which were more advanced, as in the largest tumour first described, the surface was red and granular with necrosed epidermis scales in the fissure between the tubercular outgrowths, but there was no moisture or exudation.

similar tumours were found on the dorsal aspect of the trunk, especially on the left scapula, but in none of them was the skin redlened or abrased.
The chest was slightly "barrel" shaped. 'The percussion note over the upper lobe of the right lung was somewhat impaired both back and front and there were signs of deficient air entry to this region. Fine crepitations were heard over the right apex posteriorly and the expiratory murmur over the whole of the upper lobe of this lung was prolonged and blowing. The physical signs in the other regions of the respiratory tract were healthy. In addition the patient had marked inspiratory stridor. There was slight frothy expectoration but no tubercle bacilli were discovered. A laryngoscopic examination kindly made for me by my colleague Dr. J. B. Ball showed that there was no paralysis of the vocal cords and nothing could be seen to account for the inspiratory stridlor.

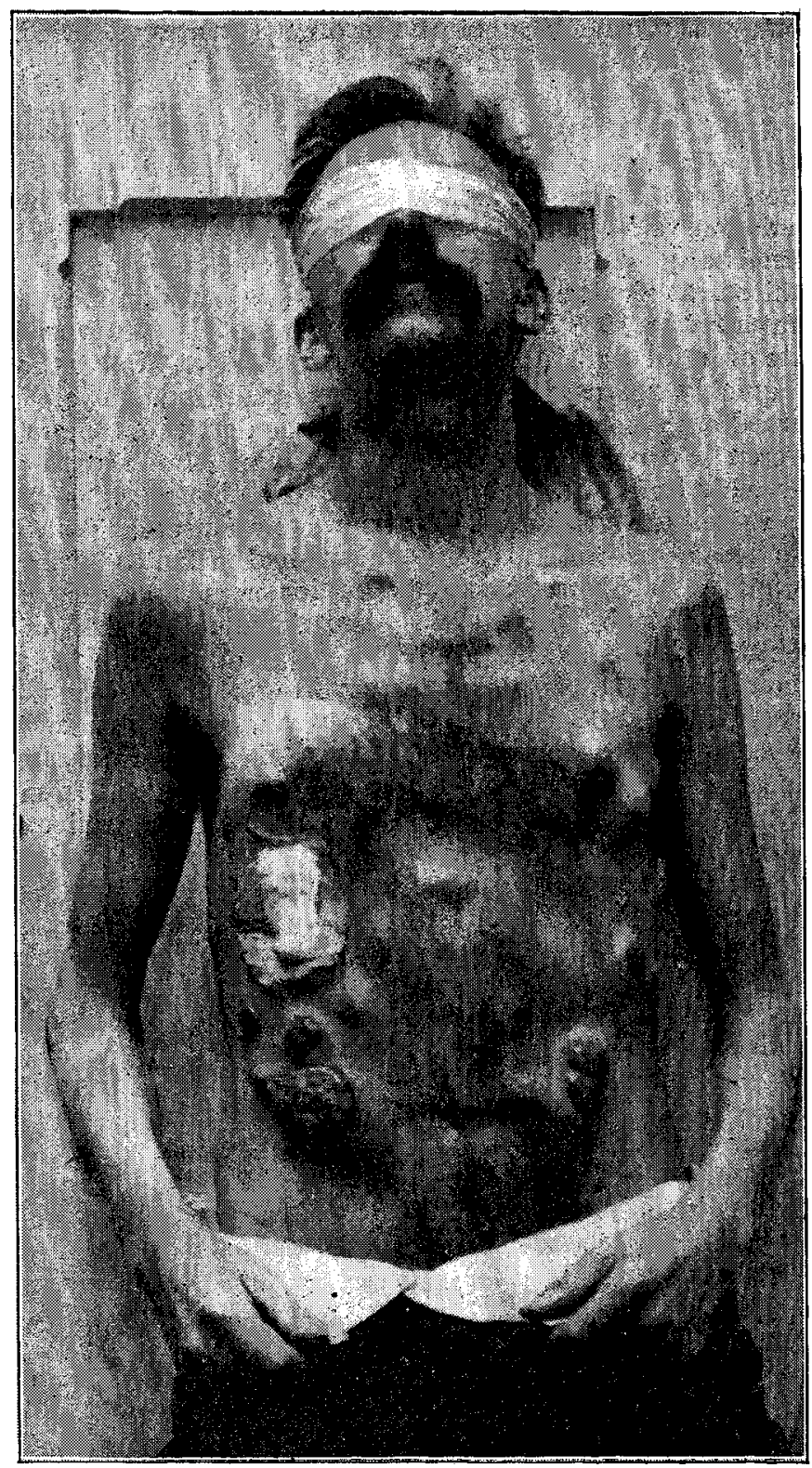

A case of multiple sarcoma.

The heart sounds were normal. The liver extended almost to the umbilicus and the lower part of its anterior surface could easily be felt-it was hard, nodular, and somewhat tender to the touch. The bladder and prostate gland were healthy. No evidence of ulceration or of new growth could be discovered by rectal examination. The urine was free from albumin and sugar and was quite normal in :pecific gravity and reaction. The bowels acted regularly. The patient complained of slight dyspnoea and cough which prevented him from sleeping and for which a linctus contain. ing opium was preseribed.'

The question of diagnosis at first was difficult to decide. The disseminated character of the growths and their rapid invasion marle one think of mycosis fungoides but the absence of a history of previous extensive skin disease (although a slight eczematous patch was still to be seen over the innor sidle of the left ankle) and the dryness of the surface of the tumours led one to reject this diagnosis.

Acting on the supposition that the disease might be tuberculous and peneling a microscopical examination of the 
tumours, shortly after admission half a grain of sodium cacodylate was injected subcutaneously twice a day. This caused pain in the tumours generally and this reaction continued so long as the injections were being made. But the sudden onset of the disease, its rapid spread and wide dissemination, and the secondary affection of the respiratory tract, which was proved to be non-tuberculous, all tended to the diagnosis of sarcoma. Meanwhile, in order to settle a definite diagnosis one of the smaller and less advanced growths was, with the patient's consent, excised, and after being duly hardened it was prepared for, and examined by, the microscope. The evidence which this afforded proved that the growths were those of sarcoma of the small roundcelled variety. An unfavourable prognosis was given and the patient shortly afterwards expressed a wish to go to his home in the country.

By the courtesy of Mr. Streeten I have heard that the patient died towards the end of February, seven months after the first signs of the disease were noticed. "The only fresh symptom which he had was urgent dyspncea in paroxysmal attacks, one of which proved fatal. No autopsy was allowed, though the patient expressed a wish that one should be made."

Seymour-street, $w$.

\section{A CASE OF ACUTE ARSENICAL POISONING.}

BY R. E. SEDGWICK, B.A., M.B., B.C. CANTAB.,

LATE SENIOR HOUSE PHYSICIAN AT THE GENERAL HOSPITAL, BIRMINGHAM.

DEATHS from acute arsenical poisoning are sufficiently rare to make the notes of such a case and of the subsequent post-mortem examination of interest and value.

On March 24th, 1903, at 5.30 A.M., I was called to see a man reported as "very ill and almost dying." On arrival at the house, 20 minutes later, I found the patient on his bed, dead. He was lying on his back with his left knee drawn up and his arms extended. His hands and feet were cold, as were also his nose and face, while his body was warm. He was well developed and well nourished but his eyes were sunken far in their sockets and a general pinched expression on his face gave him an appearance such as is frequently seen in a child with epidemic diarrhœa. The room was poorly furnished but clean; there were no signs or traces of vomited matter or fæces either in the chamber (which was empty) or about the floor and bed. On the dressing table was a glass mineralwater bottle containing about two drachms of slightly milky fluid.

The history obtained was as follows. The patient, who was a labourer at a glass-works, had always enjoyed good health. On March 23rd he was quite well, had his breakfast with the rest of the family (who were well), and went to work. He returned home about 2.30 P.M. and vomited in the entry, stating that he was "bilious." He continued to retch and to vomit and was then given a bottle of "ginger beer," after which he seemed more comfortable and dozed on the sofa. Shortly afterwards he had great abdominal pain, was violently purged, and again sick. He continued to be purged and sick until about 8 P.M., when he went to bed but without relief. As he became so weak he was asked to see a medical man but declined, stating that " he didn't want one as he was going to die." At 5 A.M. on the next morning he became so "bad" that I was sent for. All inquiries led to no elucidation of the mystery and the body and the bottle of "mineral water" were removed to the mortuary by the police and the facts were duly notified to the coroner.

Necropsy.--On March 26th, two days later, I made a postmortem examination of which the following are the notes. The body was that of a well-developed, well-nourished man, aged about 32 years, height 5 feet 9 inches. It had been in the mortuary two days (48 hours). The weather was mild and damp. The eyes were markedly shrunken in the sockets and the face had a pinched expression. No putrefactive changes were visible and there was no post-mortem rigidity. Slight venous congestion was visible on the buttocks. There were no external marks of violence. The coverings and bones of the skull were normal. The brain showed no venous hypostasis and the membranes were dry. The brain substances were normal ; there were no hæmorrhages or ecchymoses. The ventricles were dry; on section they were drier and firmer than normal. The lungs were dry and crepitant; there was no posterior hypostasis. At the apex of the right lung was an old scar which was white and contracted. The pleuræe were normal ; there were no adhesions. The left cavities of the heart were empty. There were about half an ounce of blood in the right auricle and a little clotted material in the right ventricle; otherwise the heart was normal. The tongue was clean at the tip and sides ; it was slightly furred at the back. The pharynx and cesophagus were normal; no redness or hæmorrhages were present. The stomach contained about a pint of yellow turbid fluid in which were floating several large, whitish-yellow, opaque masses. Some mucus settled on standing in which were a few green-coloured particles. The external wall of the stomach was pink in colour except for about two inches along the pyloric third of the greater curvature where it was of a dusky scarlet colour. The mesenteric glands along the greater curvature were enlarged to sizes varying from that of a bean to that of a Brazil nut and were soft, cherry-red in colour, and on section almost diffluent. Internally the mucous membrane of the stomach was thrown into folds and was generally reddened and covered with a thin layer of slimy mucus. In five or six places were patches of ecchy moses and petechiæ, chiefly lying along the greater curvature and the posterior wall, while in three places were adherent, whitish-yellow, opaque masses, surrounded by an area of scarlet-coloured and reddish-brown membrane, the largest and firmest of which corresponded to the scarlet-coloured patch on the outer wall of the greater curvature. There were no traces of food nor was there any characteristic odour. The duodenum in its first two parts was coated with slimy mucus and of brilliant red colour internally, the redness on close inspection being due to minute petechiæ. The outer covering was bile-stained and reddened. The third part together with the jejunum was completely empty except for the mucus which, indeed, lined the whole of the intestinal tract. The ileum in its lower 12 inches was slightly reddened and on one spot about eight inches above the ileo-cæcal valve was a small crater-like ulcer of the size of a pea with a smooth base and a ragged, vivid scarlet edge. Two of the neighbouring glands were swollen, soft, and red. The large intestine was empty; there was no trace of ulceration. The liver was normal in appearance; it was dry on section. The gall-bladder was empty. The pancreas and spleen were normal. Both kidneys were normal in appearance. The capsules stripped easily. The kidney substance was apparently healthy on section. A few rather bright red points of congestion were visible at the ends of the pyramids. The bladder was empty.

An inquest was held but was adjourned pending an analysis of the stomach contents, \&c. At an adjourned inquest held on April 28th inquiry elicited that the man, an agent for an insurance society, was in monetary difficulties and had been threatened with legal proceedings. He had also been seen standing near a barrel of ready-mixed "frit" (which contained arsenic) at the works about 11.30 A.M. He also vomited about noon and once or twice between noon and 1 P.M., when he left work.

Mr. H. Silvester, public analyst of the county borough of West Bromwich and Dudley, reported as follows :-

1. Contents of stomach.-One pint. Arsenic was present to the extent of $2 \cdot 17$ grains, expressed as arsenious anhydride $\left(\mathrm{A}_{4} \mathrm{O}_{6}\right)$.

2. Portion of liver (weight eight and a half ounces).-The portion of liver contained arsenic equivalent to 0.45 grain of arsenious anhydride.

3. Left kidney (weight six ounces).-The kidney contained arsenic equivalent to 0.07 grain of arsenious anhydride.

The total amount of white arsenic found was as follows: Stomach contents, 2.17 grains; liver (portion of), 0.45 grain; and left kidney, contents, 2.17 grains ; liver
0.07 grain ; total, $2 \cdot 69$ grains. Carlisle.

Wigan MEdical Society.-A meeting of this society was held on July 14th. In the absence of the President Dr. Blair was voted to the chair. After the ordinary business a paper was read (illustrated by lantern slides) by Mr. Robert Jones on Injuries about the Elbow-joint. The paper and the illustrations were very interesting and a discussion followed in which the following members took part: Dr. White, Dr. Rees, Mr. Brady, Mr. Bowen, Mr. Graham, and Dr. Blair A cordial vote of thanks was unanimously accorded to Mr. Jones for his paper. 